\title{
p53ness in Human Cancers: An Overview
}

\author{
Arindam Dasgupta ${ }^{1}$, Abhishikta Ghosh Roy ${ }^{2 *}$, Abhijit Chakraborty ${ }^{3}$ \\ ${ }^{1}$ Department of Zoology, Vivekananda College for Womens, Kolkata, India \\ ${ }^{2}$ DNA Laboratory, Anthropological Survey of India, Kolkata, India \\ ${ }^{3}$ Dept. of Clinical Research, Netaji Subhas Chandra Bose Cancer Research Institute, Kolkata, India
}

\begin{abstract}
P53, the guardian of the genome, is one of the most studied tumor suppressor gene having the ability to induce cell cycle arrest and/or apoptotic cell death in cancerous cells. Extensive mutation search reveals that $50 \%$ of human cancer can be attributed to mutations in P53 including cancers of Bladder, Breast, Cervix, Colon, Liver, Prostrate \& Lungs. P53 is located in the short arm of Chromosome 17 in Humans containing 11 exons. These homologues are sequence specific transcription factors which activate overlapping sets of P53 genes, thus inducing cell cycle arrest or apoptosis. The mutations most sensitive to the loss of function of P53 lie in the exons 5-8 which encode the DNA binding domain of P53. Under normal condition, P53 is generally inactive. But in response to different kind of stresses such as DNA damage, Hypoxia, Oxidative damage etc activates P53 by phosphorylation and dislodging and proteolysis the MDM protein that normally inhibits it during non stressful conditions. However, P53 is not a solitary gene product as it was previously thought. The present study aims to understand the role of 553 gene mutations in Human Cancer.
\end{abstract}

Keywords: P53 gene, Human Cancer, tumor suppressor, Review.

\section{INTRODUCTION}

p53 is the most commonly mutated gene in human cancers and more than $50 \%$ of human cancers contain p53 mutations Arnold Levine, David Lane and William Old discovered the p53 gene in 1979. It was first thought to be an oncogene, but10 years later team lead by Bert Vogelstein and Ray White, then studying colon cancer, showed p53 to be a tumor suppressor gene. In the past decade, the roles of p53 in human cancers have been investigated extensively in many aspects and intervention to restore wild-type p53 activities is an attractive approach for cancer therapy.

Extensive research has been directed towards targeting the p53 tumor suppressor and other key players in the DNA damage surveillance network in an attempt to improve the outcome of conventional cancer therapies [1]. This approach has met with limited success [2]. The impetus behind most of these studies has been the model, proposed in the mid 1990s, suggesting that the principal role of the p53 pathway in determining cell fate following genotoxic stress is to either promote survival by activating cell cycle checkpoints and facilitating repair or to induce apoptotic cell death [3, 4]. However, several laboratories [5-13], ours included [14-18], have demonstrated that the primary response triggered by moderate doses of DNA-damaging agents in most human cell types is a sustained proliferation block, and not apoptosis.

The proliferation block triggered by ionizing radiation predominantly reflects stress-induced premature senescence (SIPS) in p53-proficient cultures [6, 11], and the development of multinucleated and polyploid giant cells in p53-deficient cultures [5, 8]. Accumulating evidence has revealed that such responses may represent cell survival mechanisms consequent to therapeutic exposures. All cancer cells contain mutations in combinations of tumor suppressors and oncogenes. The removal of functional p53, from a cell allows for the accumulation of even more DNA damage and the division of cells that contain damaged DNA. The mutation of p53 is one of the most frequent genetic changes seen in cancer cells. In addition to mutations that arise during the growth and development of individuals (sporadic mutations), there are forms of cancer associated with the inheritance of a damaged version of p53. In addition, several viruses have evolved ways of inactivating the $\mathrm{p} 53$ protein.

p53 has been initially identified in crude cell lysates prepared from cells transformed by simian virus 40 (SV40) [1-5]. Subsequent studies demonstrated that p53 forms a stable complex in SV40transfromed cells with SV40 large T antigen which has an oncogenic potential, and p53 had an ability 
to promote tumor growth. In support with these results, p53 was detectable in a variety of tumorderived cell lines [1, 3, 4]. Based on these observations, p53 came to be classified as an oncogene [6]. However, this classical point of view has been challenged by the findings showing that the initially discovered p53 is a mutant form of p53 [7]. In a sharp contrast to mutant forms of p53, subsequent studies revealed that wild-type p53 is capable to suppress the malignant growth of transformed cells as well as tumors, suggesting that p53 acts as a tumor suppressor [8-12]. Intriguingly, p53 gene (Figure 1) locates on the short arm of human chromosome 17 (17p13), where loss of heterozygosity $(\mathrm{LOH})$ was detectable in a wide variety of tumor tissues. It is worth noting that the remaining non deleting p53 allele is mutated in some cases [13-18]. Extensive mutation searches demonstrated that over $50 \%$ of human tumors carry p53 mutations. Indeed, p53-deficient mice developed spontaneous tumors at a relatively young age [19].

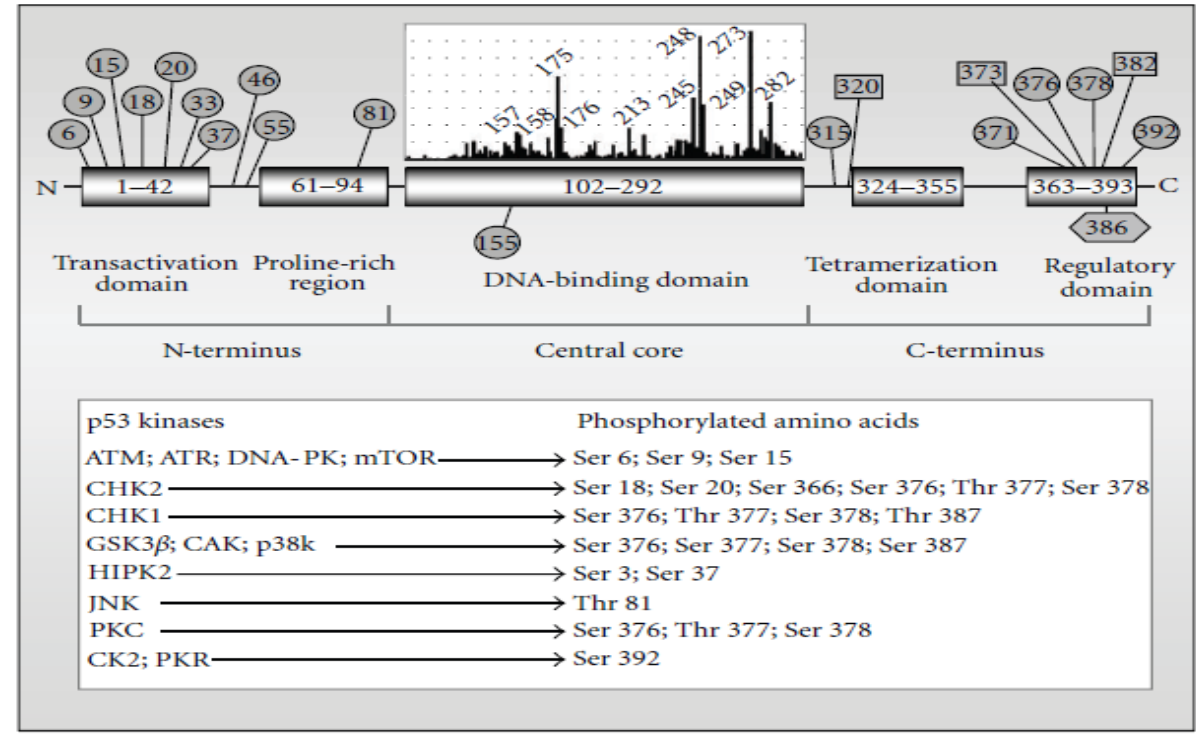

Figure 1.p53 gene details

Ninety-five percent of the mutations were detected within the central sequence-specific DNA-binding region of p53 [20-22]. These mutations disrupted the whole conformation of the sequence-specific DNA-binding domain of p53 and resulted in the loss of its sequence-specific DNA binding ability [23]. Since p53 was a nuclear sequence specific transcription factor which transactivated a set of its target genes involved in the induction of cell cycle arrest and/or apoptotic cell death, mutant forms of p53 lacked their critical function to maintain the genomic integrity. Furthermore, mutant forms of p53 has acquired a much longer half-life as compared with that of wild-type p53 [24, 25] and displayed a dominant-negative behavior toward wild-type p53 [26, 27]. This dominant-negative effect of mutant p53 on wild-type p53 might be mediated by the hetero-oligomerization through their oligomerization domains [7, 28-30]. In this connection, p53 mutation conferred the resistance of tumor cells to anticancer drugs by inhibiting p53-dependent proapoptotic pathway [31-33].

p53 had a strong proapoptotic activity. Under normal conditions, the expression level of this dangerous protein is kept at extremely low level. In response to multiple cellular stresses including DNA damage, oncogene activation, hypoxia, nucleotide imbalance, and oxidative damage, p53 was rapidly accumulated in cell nucleus through chemical modifications such as phosphorylation and acetylation and exerted its proapoptotic function to remove cells with seriously damaged DNA in which DNA damage was severe and repair was impossible [22, 34-36]. In this case, p53 transactivated proapoptotic

target genes including BAX, PUMA, NOXA, and p53AIP1, and the collaboration of these gene products contributed to the disruption of mitochondrial membrane potential, which was a critical step in p53dependent proapoptotic pathway [37]. On the other hand, p53 promoted G1 cell cycle arrest in the early stage of DNA damage response through the transactivation of $p 21 W A F 1, p 53 R 2$ and GADD45 implicated in the induction of cell cycle arrest and DNA repair [37]. After DNA repair had been completed, cells reentered into normal cell cycle. Upon DNA damage, cells underwent either cell cycle arrest or apoptotic cell death to allow DNA repair or suicide of cells, which was dependent on the degree and/or the nature of DNA damage. 
For a long time, p53 has been considered to be a solitary gene product. Due to the improvement of cloning technologies, Kaghad et al. identified the first p53 homolog termed p73 [38]. Additionally, Yang et al. discovered the second p53 homolog termed p63 [39]. Cell-based studies demonstrated that p73 and p63 act as nuclear sequencespecific transcription factors which transactivate the overlapping set of p53-target genes and also have an ability to induce cell cycle arrest and/or apoptotic cell death in cancerous cells $[40,41]$. Like p53, p73, and p63 were induced in response to a certain subset of DNA-damaging agents $[42,43]$. Thus, p53 becomes a foundingmember of p53 tumor suppressor family composed of p53, p73 and p63.

\section{P53 Gene - General Features}

p53 locates at a short arm of human chromosome 17 p13 containing 11 exons spanning $20 \mathrm{~kb}$. p53 acts as a nuclear sequence-specific transcription factor composed of $\mathrm{NH} 2$ - terminal transactivation domain (TA, amino acid residues 1-45), central sequence-specific DNA-binding domain (DB, amino acid residues 102-292), and $\mathrm{COOH}$-terminal oligomerization domain (OD, amino acid residues 319-359).

In addition to these representative functional domains, p53 contains three nuclear localization signals (NLS, amino acid residues 305-322, 369-375, and 379-384) recognized by importin á/â complex [44], a Leu-rich nuclear export signal (NES, amino acid residues 339-352) recognized by CRM1(chromosomal region maintenance 1) [44], and a Pro-rich domain (amino acid residues 63-97). Cytoplasmic retention

of p53 was observed in certain breast cancer-derived cells expressing the truncated form of importin á, indicating that importin á plays an essential role in nuclear import of p53 [45]. Cytoplasmic p53 is nonfunctional. Pro-rich domain has been shown to be associated with proapoptotic activity of p53 [46, 47]. Deletion of this Pro-rich region resulted in a complete loss of proapoptotic activity of p53. Active form of nuclear $\mathrm{p} 53$, which functions as a tetramer, recognizes and binds to a consensus sequence motif made of tandem 10 bp elements (RRRCWWGYYY: R, G/A; W, A/T; Y, C/T) separated by 1$13 \mathrm{bp}$ found within the promoter regions of p53-target genes. p53 exerts its proapoptotic function through the transactivation of its target genes $[48,49]$. Genome-wide analysis revealed that there exist over 4,000 putative p53-responsive elements [22]. Although all of these canonical p53-responsive elements might not always be functional, identification and functional analysis of new p53-target genes provide novel insights into understanding the precise molecular mechanisms behind p53dependent proapoptotic pathway.

Since the sequence-specific DNA-binding ability of p53 is tightly linked to its proapoptotic activity $[48,49]$, the genomic integrity of p53 gene encoding the sequence specific DNA-binding domain (exons 5-8) is particularly important. Extensive mutation search revealed that over 50\% of human tumors carry p53 mutations [20,21]. Among these mutations, 95\% of them occurred within the genomic region encoding the sequence-specific DNA-binding domain of $\mathrm{p} 53$. These mutations disrupted the proper conformation

of the sequence-specific DNA-binding domain of p53, and thus mutant forms of p53 lacked the sequence-specific transactivation ability. In contrast to the short-lived wildtype p53, mutant forms of p53 had a longer half-life [24, 25]. Moreover, mutant forms of p53 exhibited an oncogenic potential [50] and displayed the dominant-negative behavior toward wild-type p53 [26, 27], suggesting that mutant forms of p53 attenuate p53-dependent proapoptotic pathway (Figure 1).

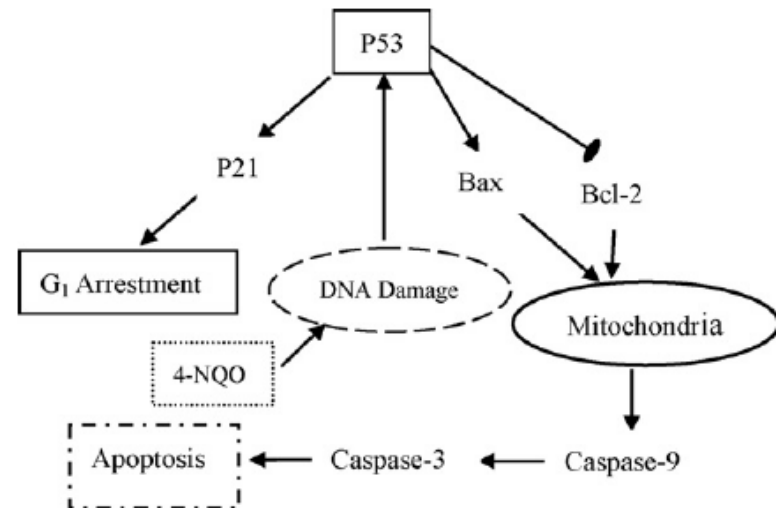

Figure 2. p53-dependent proapoptotic pathway 
Since the previous mutation search for $\mathrm{p} 53$ gene focused on the genomic region encoding the central core sequencespecific DNA-binding domain of p53, it is likely that there could exist the unidentified mutations outside the central core sequence-specific DNA-binding domain. Indeed, Lomax et al. found point mutations (L344P and R337C) within the COOH-terminal oligomerization domain [51, 52]. Similarly, Di Giammarino et al. reported the presence of a point mutation (R337H) within the $\mathrm{COOH}$-terminal oligomerization domain [53]. In addition to these mutations, we have found p53 $\mathrm{A} C$ lacking a part of the $\mathrm{COOH}$-terminal oligomerization domain and nuclear localization signals in human neuroblastoma-derived cell lines [54]. According to our results, p53 ÄC was largely expressed in cytoplasm and had a significantly lower proapoptotic ability as compared with wild-type p53.

\section{Mutational InaCtivation OF P53}

Mutational inactivation is considered to be one of the most common molecular mechanisms behind the dysfunction of p53. Extensive mutation search revealed that more than half of human cancers carry loss of function mutations of p53 [16]. Among them, 95\% of mutations were detectable within the genomic region (exons 5-8) encoding the DNA-binding domain [4]. The close inspection of the mutation profiles revealed that the six amino acid residues are most frequently mutated in human cancers including Arg-175, Gly-245, Arg-248, Arg-249, Arg-273 and Arg-282 [38]. These mutations found within the DNA-binding domain of p53 disrupt its proper conformation and thus the mutant p53 is defective in the sequence-specific transcriptional activation dependent on the wild-type p53binding consensus element. Furthermore, mutant p53 displays a dominant-negative behavior toward wild-type p53 through the formation of hetero-tetramer with wild-type p53 and has oncogenic potential $[21,22,25]$. The accumulating evidence demonstrated that certain cancer-derived mutant forms of p53 transactivate various target genes such as the multiple drug resistance gene 1 (MDR1), c-myc, proliferating cell nuclear antigen (PCNA), interleukin-6 (IL-6), insulin-like growth factor 1 (IGF-1), fibroblast growth factor (FGF) and epidermal growth factor receptor (EGFR) [39-45]. Scian et al. found that cancer-derived mutant p53 transactivates aspargine synthetase (ASNS) and telomerase reverse transcriptase (TERT) [46]. Therefore, it is likely that certain cancer-derived p53 mutants transactivate growth-promoting and oncogenic genes, thereby leading to the progression of the aggressive cancers. Since the mutation search for $\mathrm{p} 53$ focused on the genomic region encoding the DNA-binding domain, there could still be unidentified loss of function mutations outside the DNAbinding domain [4]. Lomax et al. found point mutations (L344P and R337C) within the COOHterminal oligomerization domain of p53 [47,48]. According to their results, p53 bearing L344P mutation existed as the monomeric form and lacked the transactivation ability. On the other hand, p53 carrying R377C mutation formed the tetramer, whereas this mutant displayed the significantly reduced transcriptional and pro-apoptotic activities. DiGiammarino et al. reported the presence of a point mutation $(\mathrm{R} 337 \mathrm{H})$ within the $\mathrm{COOH}$-terminal oligomerization domain [49]. p53 bearing $\mathrm{R} 337 \mathrm{H}$ mutation formed the native-like tetramer, however, its stability was significantly lower than that of wild-type p53. We have found p53 $\Delta \mathrm{C}$ lacking a part of the oligomerization domain and nuclear localization signals in human neuroblastoma-derived cell lines [50]. Based on our results, p53 $\Delta \mathrm{C}$ largely expressed in cytoplasm and had significantly lower pro-apoptotic ability as compared with wild-type p53. Therefore, p53 mutations detected outside the DNA-binding domain also caused loss of function of p53. From the clinical point of view, a novel strategy to eliminate the negative effect of mutant p53 on wild-type p53 needs to be developed. Although the great majority of p53 mutants exert a dominant-negative effect onwild-type p53, some of p53 mutants such as R175P display only partial loss of their DNA-binding activity [5].

\section{VARIANT FORMS}

Yin et al. detected full-length wild-type p53 and another p53 with a relative molecular mass of 47 KDa termed p53/47 [94]. p53/47 was detectable by the 421 monoclonal antibody which recognized $\mathrm{COOH}$-terminal portion of p53 and also detectable by the 1801 antibody which recognized an epitope between amino acid residues 46 and 55. On the other hand, the DO-1 (amino acid residues 20-25) and the DO-

13 (amino acid residues 26-35) failed to recognize p53/47. Subsequent study demonstrated that p53/47 is generated from the NH2-terminal alternative initiation site (Met-40). Since p53/47 lacked an NH2-terminal MDM2-binding domain, it was not targeted for proteasome-dependent degradation by MDM2. Previous studies indicate that NH2-terminal transactivation domain of p53 is divided into two independent domains such as TA 1 (amino acid residues 1-40) and TA II (amino acid residues 43-63) 
[89-94]. p53/47 lacked TA I domain but contained TA II domain. Of note, p53/47 failed to transactivate $p 21 W A F 1$ but was able to induce the transcription of $M D M 2, G A D D 45$, and BAX. These observations suggest that TA I and TA II domains contribute to enhance the specificity of p53-target promoter usage [89].

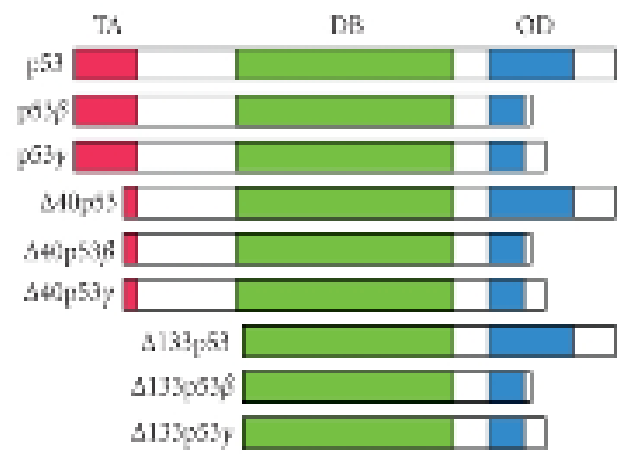

Figure 3

In addition to the alternative translation product of $\mathrm{p} 53$, Bourdon et al. found the presence of multiple variant forms of p53 arising from alternative promoter usage and alternative splicing events [74-78]. Based on their results, they identified the alternative promoter located within intron 4, and mRNA transcribed from this internal promoter generated NH2-terminally truncated form of p53 initiated at codon $133(\Delta 133 \mathrm{p} 53)$, which lacked NH2-terminal transactivation domain and Pro-rich domain. Further studies demonstrated that the alternative splicing of intron 9 results in the generation of $\mathrm{p} 53 \beta$ and $\mathrm{p} 53 \gamma$, which deleted the $\mathrm{COOH}$-terminal oligomerization domain. Thus, $\mathrm{p} 53$ is expressed as multiple variants including $\mathrm{p} 53, \mathrm{p} 53 \beta, \mathrm{p} 53 \gamma, \Delta 133 \mathrm{p} 53, \Delta 133 \mathrm{p} 53 \beta, \Delta 133 \mathrm{p} 53 \gamma, \Delta 40 \mathrm{p} 53, \Delta 40 \mathrm{p} 53 \beta$, and $\Delta 40 \mathrm{p} 53 \gamma . \Delta 40 \mathrm{p} 53$ corresponds to $\mathrm{p} 53 / 47$.

Immunostaining experiments revealed that most of these p53 variants were localized largely in cell nucleus, whereas p53 $\gamma$ was detectable both in cell nucleus and cytoplasm. Additionally, $\Delta 133 \mathrm{p} 53 \gamma$ was localized exclusively in cytoplasm. p53 variants had an ability to bind differentially to p53responsive promoters and modulated p53- target gene expression. For example, p53 $\beta$ bound preferentially to $B A X$ and $p 21 W A F 1$ promoters rather than $M D M 2$ promoter, whereas p53 bound preferentially to $p 21 W A F 1$ and $M D M 2$ promoters than to $B A X$ promoter [81-83].

\section{DisCUSSION}

Since over $50 \%$ of human cancers carry p53 mutations, mutational inactivation is a major molecular mechanism behind p53 dysfunction. Cancers bearing p53 mutation sometimes display a chemoresistant phenotype. Although the intracellular balance between the expression levels of wild-type p53 and mutant p53 might be a critical determinant of cell fate in response to DNA damage, mutant p53 acts as a dominant-negative inhibitor toward wild-type p53 and exhibits a longer half-life than wildtype p53. Thus, the development of novel strategies to re-activate mutant p53 is required to provide clues to effectively treat malignant cancers bearing p53 mutations. p53 plays a pivotal role in the regulation of cell fate determination in response to a variety of cellular stresses. Dysfunction of p53 such as mutational inactivation permits the abnormal cell growth and finally results in the malignant tumor development. In addition, loss of function of p53 contributes to the significant decrease in the sensitivity of tumor cells to anticancer drugs.

Therefore, the elucidation of the precise molecular mechanisms behind stress-induced activation of p53 might provide a clue(s) to find out the attractive therapeutic target(s) for cancer treatment. In contrast to p73and p63, p53 is frequently mutated in human tumors. Mutant forms of p53 lack their proapoptotic function and display a dominant-negative behavior toward wildtype p53 family. Further efforts should be required to develop the novel strategies and/or the chemical compounds which could convert the abnormal conformations of mutant p53 to normal ones. In this connection, one of the remaining questions is that why p53 is frequently mutated in tumor tissues. Although it could be due to the serious defects in the DNA repair machinery in these tumors, further studies should be required to address this issue. p53, located in human chromosome 17, is a gene with tumor suppressor activities. This protein contains 393 amino acids and a single amino acid substitution lead to loss of function of the gene. 
Mutations at amino acids 175, 248, and 273 can lead to loss of function and changes at 273 (13\%) are the most common. All these act as recessive mutations. Dominant gain-of-function mutations have also found that lead to uncontrolled cell division. Because these mutations can be expressed in heterozygous conditions, they are often associated with cancers. This genetic function of this gene is to prevent cell division of cells with damaged DNA. Damaged DNA could contain genetic changes that promote uncontrolled cell growth. Therefore, preventing cell division until damaged DNA is repaired is one mechanism of preventing the onset of cancer. About $50 \%$ of human cancers can be associated with a p53 mutation including cancers of the bladder, breast, cervix, colon, lung, liver, prostrate, and skin. p53 related cancers are also more aggressive and have a higher degree of fatalities. Several gene therapeutic strategies have been employed in the attempt to restore p53 function to cancerous cells. These approaches include introduction of wild-type p53 into p53 mutant cells; the use of small molecules to stabilize mutant p53 in a wildtype, active conformation; and the introduction of agents to prevent degradation of p53 by proteins that normally target it. In addition, because mutant p53 has gain of function activity, several approaches have been investigated to selectively target and kill cells harboring mutant $\mathrm{p} 53$. These include the introduction of mutant viruses that cause cell death only in cells with mutant p53 and the introduction of a gene that, in the absence of functional p53, produces a toxic product. Many obstacles remain to optimize these strategies for use in humans, but, despite these, restoration of p53 function is a promising anti cancer therapeutic approach.

\section{REFERENCES}

[1] T. Zhang, P. Brazhnik, and J. J. Tyson, "Exploring mechanisms of the DNA-damage response: p53 pulses and their possible relevance to apoptosis," Cell Cycle, vol. 6, no. 1, pp. 85-94, 2007.

[2] N. Desilet, T. N. Campbell, and F. Y. M. Choy, "p53-based anti-cancer therapies: an empty promise?" Current Issues in Molecular Biology, vol. 12, no. 3, pp. 143-146, 2010.

[3] T. Enoch and C. Norbury, "Cellular responses to DNA damage: cell-cycle checkpoints, apoptosis and the roles of p53 and ATM," Trends in Biochemical Sciences, vol. 20, no. 10, pp. 426-430, 1995.

[4] M. S. Meyn, "Ataxia-telangiectasia and cellular responses to DNA damage," Cancer Research, vol. 55, no. 24, pp. 5991-6001, 1995.

[5] I.B. Roninson, E. V. Broude, and B. D. Chang, "If not apoptosis, then what? Treatment-induced senescence and mitotic catastrophe in tumor cells," Drug Resistance Updates, vol. 4, no. 5, pp. 303-313, 2001.

[6] I.B. Roninson, "Tumor cell senescence in cancer treatment," Cancer Research, vol. 63, no. 11, pp. 2705-2715, 2003.

[7] Z. Han, W. Wei, S. Dunaway et al., "Role of p21 in apoptosis and senescence of human colon cancer cells treated with camptothecin," Journal of Biological Chemistry, vol. 277, no. 19, pp. 17154-17160, 2002.

[8] M. Castedo, J. L. Perfettini, T. Roumier, K. Andreau, R.Medema, and G. Kroemer, "Cell death by mitotic catastrophe: a molecular definition," Oncogene, vol. 23, no. 16, pp.2825-2837, 2004.

[9] D. Sohn, F. Essmann, K. Schulze-Osthoff, and R. U. J"anicke,"p21 blocks irradiation-induced apoptosis downstream of mitochondria by inhibition of cyclin-dependent kinase mediated caspase-9 activation," Cancer Research, vol. 66, no.23, pp. 11254-11262, 2006.

[10] G. Afshar, N. Jelluma, X. Yang et al., "Radiation-induced caspase-8 mediates p53-independent apoptosis in glioma cells," Cancer Research, vol. 66, no. 8, pp. 4223-4232, 2006.

[11] D. A. Gewirtz, S. E. Holt, and L. W. Elmore, "Accelerated senescence:an emerging role in tumor cell response to chemotherapy and radiation," Biochemical Pharmacology, vol. 76, no. 8, pp. 947-957, 2008.

[12] M. A. Sliwinska, G. Mosieniak, K. Wolanin et al., "Induction of senescence with doxorubicin leads to increased genomic instability of HCT116 cells," Mechanisms of Ageing and Development, vol. 130, no. 1-2, pp. 24-32, 2009.

[13] S. Mansilla, M. Bataller, and J. Portugal, "A nuclear budding mechanism in transiently arrested cells generates drug-sensitive and drug-resistant cells," Biochemical Pharmacology, vol. 78, no. 2, pp. 123-132, 2009. 
[14] R. D. C. Barley, L. Enns, M. C. Paterson, and R. Mirzayans, "Aberrant p21WAF1-dependent growth arrest as the possible mechanism of abnormal resistance to ultraviolet lightcytotoxicity in Li-Fraumeni syndrome fibroblast strains heterozygous for TP53 mutations," Oncogene, vol. 17, no. 5, pp. 533-543, 1998.

[15] R.Mirzayans, A. Scott, M. Cameron, and D.Murray, "Induction of accelerated senescence by $\gamma$ radiation in human solid tumor-derived cell lines expressing wild-type TP53," RadiationResearch, vol. 163, no. 1, pp. 53-62, 2005.

[16] R. Mirzayans and D. Murray, "Cellular senescence: implications for cancer therapy," in Monograph, R. B. Garvey, Ed.,pp. 1-130, Nova Science Publishers, Hauppauge, NY, USA, 2009.

[17] R.Mirzayans, A. Scott, B. Andrais, S. Pollock, and D.Murray,“Ultraviolet light exposure triggers nuclear accumulation of p21WAF1 and accelerated senescence in human normal and nucleotide excision repair-deficient fibroblast strains," Journal of Cellular Physiology, vol. 215, no. 1, pp. 55-67, 2008.

[18] R. Mirzayans, B. Andrais, A. Scott, M. C. Paterson, and D.Murray, "Single-cell analysis of p16INK4a and p21WAF1 expression suggests distinct mechanisms of senescence in normal human and Li-Fraumeni syndrome fibroblasts," Journal of ellular Physiology, vol. 223, no. 1, pp. 57-67, 2010.

[19] I. B. Roninson, "Tumor cell senescence in cancer treatment,"Cancer Research, vol. 63, no. 11, pp. 2705-2715, 2003.

[20] D. A. Gewirtz, S. E. Holt, and L. W. Elmore, "Accelerated senescence: an emerging role in tumor cell response to chemotherapy and radiation," Biochemical Pharmacology, vol. 76, no. 8, pp. 947-957, 2008.

[21] M. Castedo, J. L. Perfettini, T. Roumier, K. Andreau, R.Medema, and G. Kroemer, "Cell death by mitotic catastrophe: a molecular definition," Oncogene, vol. 23, no. 16, pp. 2825-2837, 2004.

[22] A.B. DeLeo, G. Jay, and E. Appella, "Detection of a transformation-related antigen in chemically induced sarcomas and other transformed cells of the mouse,"Proceedings of the National Academy of Sciences of the United States of America, vol. 76, no. 5, pp. 24202424,1979 .

[23] M. Kress, E. May, R. Cassingena, and P. May, "Simian virus 40-transformed cells express new species of proteins precipitable by anti-simian virus 40 tumor serum," Journal of Virology, vol. 31, no. 2, pp. 472-483, 1979.

[24] D. P. Lane and L. V. Crawford, "T antigen is bound to a host protein in SV40 transformed cells," Nature, vol. 278, no. 5701, pp. 261-263, 1979.

[25] D. I. H. Linzer and A. J. Levine, "Characterization of a 54K dalton cellular SV40 tumor antigen present in SV40 transformed cells and uninfected embryonal carcinoma cells," Cell, vol. 17, no. 1, pp. 43-52, 1979.

[26] J. A. Melero, D. T. Stitt, W. F. Mangel, and R. B. Carroll, "Identification of new polypeptide species (48-55K) immunoprecipitable by antiserumto purified large $\mathrm{T}$ antigen and present in SV40-infected and -transformed cells," Virology, vol. 93, no. 2, pp. 466-480, 1979.

[27] A.J. Levine, J. Momand, and C. A. Finlay, “The p53 tumour suppressor gene,” Nature, vol. 351, no. 6326, pp. 453-456, 1991.

[28] A.A. Finlay, P.W. Hinds, and A. J. Levine, "The p53 protooncogene can act as a suppressor of transformation," Cell, vol. 57, no. 7, pp. 1083-1093, 1989.

[29] A.Eliyahu, D. Michalovitz, S. Eliyahu, O. Pinhasi-Kimhi and M.Oren, "Wild-type p53 can inhibit oncogene-mediated focus formation," Proceedings of the National Academy of Sciences of the United States of America, vol. 86, no. 22, pp. 8763-8767, 1989.

[30] S. J. Baker, S. Markowitz, E. R. Fearon, J. K. V.Willson, and B. Vogelstein, "Suppression of human colorectal carcinoma cell growth by wild-type p53," Science, vol. 249, no. 4971, pp. 912-915, 1990.

[31] L. Diller, J. Kassel, C. E. Nelson et al., "p53 functions as a cell cycle control protein in osteosarcomas," Molecular and Cellular Biology, vol. 10, no. 11, pp. 5772-5781, 1990.

[32] D. Michalovitz, O. Halevy, and M. Oren, "Conditional inhibition of transformation and of cell proliferation by a temperature-sensitive mutant of p53," Cell, vol. 62, no. 4, pp. 671-680, 1990. 
[33] J. Martinez, I. Georgoff, J. Martinez, and A. J. Levine, "Cellular localization and cell cycle regulation by a temperaturesensitive p53 protein," Genes and Development, vol. 5, no. 2, pp. 151-159, 1991.

[34] S. J. Baker, E. R. Fearon, J. M. Nigro et al., "Chromosome 17 deletions and p53 gene mutations in colorectal carcinomas," Science, vol. 244, no. 4901, pp. 217-221, 1989.

[35] J. M. Nigro, S. J. Baker, A. C. Preisinger et al., "Mutations in the p53 gene occur in diverse human tumour types," Nature, vol. 342, no. 6250, pp. 705-708, 1989.

[36] T. Takahashi, M. M. Nau, I. Chiba et al., "p53: a frequent target for genetic abnormalities in lung cancer," Science, vol. 246, no. 4929, pp. 491-494, 1989.

[37] Z. Kelman, M. Prokocimer, S. Peller et al., "Rearrangements in the p53 gene in Philadelphia chromosome positive chronic myelogenous leukemia," Blood, vol. 74, no. 7, pp. 2318-2324, 1989.

[38] B. Vogelstein, “Cancer. A deadly inheritance,” Nature, vol. 348, no. 6303, pp. 681-682, 1990.

[39] R. Iggo, K. Gatter, J. Bartek, D. Lane, and A. L. Harris, "Increased expression of mutant forms of p53 oncogene in primary lung cancer," Lancet, vol. 335, no. 8691, pp. 675-679, 1990.

[40] L. A. Donehower, M. Harvey, B. L. Slagle et al., "Mice deficient for p53 are developmentally normal but susceptible to spontaneous tumours," Nature, vol. 356, no. 6366, pp. 215-221, 1992.

[41] M. Hollstein, B. Shomer, M. Greenblatt et al., "Somatic point mutations in the p53 gene of human tumors and cell lines: updated compilation," Nucleic Acids Research, vol. 24, no. 1, pp. 141-146, 1996.

[42] M. Hollstein, M. Hergenhahn, Q. Yang, H. Bartsch, Z.-Q. Wang, and P. Hainaut, "New approaches to understanding p53 gene tumor mutation spectra," Mutation Research, vol. 431, no. 2, pp. 199-209, 1999.

[43] K. H. Vousden and X. Lu, "Live or let die: the cell's response to p53," Nature Reviews Cancer, vol. 2, no. 8, pp. 594-604, 2002.

[44] Y. Cho, S. Gorina, P. D. Jeffrey, and N. P. Pavletich, "Crystal structure of a p53 tumor suppressor-DNA complex: understanding tumorigenic mutations," Science, vol. 265, no. 5170, pp. 346-355, 1994.

[45] L.V.Crawford, D. C. Pim, and P. Lamb, "The cellular protein p53 in human tumours," Molecular Biology and Medicine, vol. 2, no. 4, pp. 261-272, 1984.

[46] G. Cattretti et al., "p53 expression in breast cancer," International Journal of Cancer, vol. 41, pp. 178-183, 1986.

[47] S. E. Kern, J. A. Pietenpol, S. Thiagalingam, A. Seymour, K. W. Kinzler, and B. Vogelstein, "Oncogenic forms of p53 inhibit p53-regulated gene expression," Science, vol. 256, no. 5058, pp. 827-830, 1992.

[48] M. Hachiya, A. Chumakov, C. W. Miller, M. Akashi, J. Said, and H. P. Koeffler, "Mutant p53 proteins behave in a dominant, negative fashion in vivo," Anticancer Research, vol. 14, no. 5, pp. 1853-1859, 1994.

[49] B. Rovinski and S. Benchimol, "Immortalization of rat embryo fibroblasts by the cellular p53 oncogene," Oncogene, vol. 2, no. 5, pp. 445-452, 1988.

[50] D. Eliyahu, N. Goldfinger, O. Pinhasi-Kimhi et al., "Fibrosarcoma cells express two transforming mutant p53 species," Oncogene, vol. 3, no. 3, pp. 313-321, 1988.

[51] M. R. Green, "When the products of oncogenes and antioncogenes meet," Cell, vol. 56, no. 1, pp. 1-3, 1989.

[52] B. Vogelstein and K.W. Kinzler, "p53 Function and dysfunction," Cell, vol. 70, no. 4, pp. $523-$ 526, 1992.

[53] V. E. Velculescu and W. S. El-Deiry, "Biological and clinical importance of the p53 tumor suppressor gene," Clinical Chemistry, vol. 42, no. 6, pp. 858-868, 1996.

[54] B. Vogelstein, D. Lane, and A. J. Levine, "Surfing the p53 network," Nature, vol. 408, no. 6810, pp. 307-310, 2000.

[55] R. V. Sionov and Y. Haupt, "The cellular response to p53: the decision between life and death," Oncogene, vol. 18, no. 45, pp. 6145-6157, 1999. 
[56] C. Prives and P. A. Hall, "The P53 pathway,” Journal of Pathology, vol. 187, no. 1, pp. 112-126, 1999.

[57] W. S. El-Deiry, "The role of p53 in chemosensitivity and radiosensitivity," Oncogene, vol. 22, no. 47, pp. 7486-7495, 2003.

[58] M. Lacroix, R.-A. Toillon, and G. Leclercq, "p53 and breast cancer, an update," EndocrineRelated Cancer, vol. 13, no. 2, pp. 293-325, 2006.

[59] M. Kaghad, H. Bonnet, A. Yang et al., "Monoallelically expressed gene related to p53 at 1p36, a region frequently deleted in neuroblastoma and other human cancers," Cell, vol. 90, no. 4, pp. 809-819, 1997.

[60] G.Melino, V. De Laurenzi, and K. H. Vousden, "p73: friend or foe in tumorigenesis," Nature Reviews Cancer, vol. 2, no. 8, pp. 605-615, 2002.

[61] T. Ozaki and A. Nakagawara, "p73, a sophisticated p53 family member in the cancer world," Cancer Science, vol. 96, no. 11, pp. 729-737, 2005.

[62] M. S. Irwin, K. Kondo, M. C. Marin, L. S. Cheng, W. C.Hahn, and W. G. Kaelin Jr., "Chemosensitivity linked to p73 function," Cancer Cell, vol. 3, no. 4, pp. 403-410, 2003.

[63] Y. Suenaga, T. Ozaki, Y. Tanaka et al., "TATA-binding protein (TBP)-like protein is engaged in etoposide-induced apoptosis through transcriptional activation of human TAp63 gene," Journal of Biological Chemistry, vol. 284, no. 51, pp. 35433-35440, 2009.

[64] M. Fabbro and B. R. Henderson, "Regulation of tumor suppressors by nuclear-cytoplasmic shuttling," Experimental Cell Research, vol. 282, no. 2, pp. 59-69, 2003.

[65] I.-S. Kim, D.-H. Kim, S.-M. Han et al., "Truncated form of importin $\alpha$ identified in breast cancer cell inhibits nuclear import of p53," Journal of Biological Chemistry, vol. 275, no. 30, pp. 23139-23145, 2000.

[66] K. K. Walker and A. J. Levine, "Identification of a novel p53 functional domain that is necessary for efficient growth suppression," Proceedings of the National Academy of Sciences of the United States of America, vol. 93, no. 26, pp. 15335-15340, 1996.

[67] N. Baptiste, P. Friedlander, X. Chen, and C. Prives, "The proline-rich domain of p53 is required for cooperation with anti-neoplastic agents to promote apoptosis of tumor cells," Oncogene, vol. 21, no. 1, pp. 9-21, 2002.

[68] W. S. El-Deiry, S. E. Kern, J. A. Pietenpol, K. W. Kinzler, and B. Vogelstein, "Definition of a consensus binding site for p53," Nature Genetics, vol. 1, no. 1, pp. 45-49, 1992.

[69] J. A. Pietenpol, T. Tokino, S. Thiagalingam, W. S. El- Deiry, K. W. Kinzler, and B. Vogelstein, "Sequence-specific transcriptional activation is essential for growth suppression by p53," Proceedings of the National Academy of Sciences of the United States of America, vol. 91, no. 6, pp. 1998-2002, 1994.

[70] P.-L. Chen, Y. Chen, R. Bookstein, and W.-H. Lee, "Genetic mechanisms of tumor suppression by the human p53 gene," Science, vol. 250, no. 4987, pp. 1576-1580, 1990.

[71] M. E. Lomax, D. M. Barnes, R. Gilchrist, S. M. Picksley, J. M. Varley, and R. S. Camplejohn, "Two functional assays employed to detect an unusual mutation in the oligomerisation domain of p53 in a Li-Fraumeni like family," Oncogene, vol. 14, no. 15, pp. 1869-1874, 1997.

[72] M. E. Lomax, D. M. Barnes, T. R. Hupp, S. M. Picksley, and R. S. Camplejohn, "Characterization of p53 oligomerization domain mutations isolated from Li-Fraumeni and iFraumeni like family members," Oncogene, vol. 17, no. 5, pp. 643-649, 1998.

[73] Y. Nakamura, T. Ozaki, H. Niizuma, M. Ohira, T. Kamijo, and A. Nakagawara, "Functional characterization of a new p53 mutant generated by homozygous deletion in a neuroblastoma cell line," Biochemical and Biophysical Research Communications, vol. 354, no. 4, pp. 892-898, 2007.

[74] Hollstein, M.; Sidransky, D.; Vogelstein, B.; Harris, C.C. p53 mutations in human cancers. Science 1991, 253, 49-53.

[75] Vousden, K.H.; Lu, X. Live of let die: The cell's response to p53. Nat. Rev. Cancer 2002, 2, 594604.

[76] Joerger, A.C.; Fersht, A.R. Structure-function-rescue: the diverse nature of common p53 cancer mutants. Oncogene 2007, 26, 2226-2242. 
[77] Herskowitz, I. Functional inactivation of genes by dominant negative mutations. Nature 1987, 329, 219-222.

[78] Herskowitz, I. A regulatory hierarchy for cell specialization in yeast. Nature 1989, 342, 749-757.

[79] Chen, P.L.; Chen, Y.M.; Bookstein, R.; Lee, W.H. Genetic mechanisms of tumor suppression by the human p53 gene. Science 1990, 250, 1576-80.

[80] Chin, K.V.; Ueda, K.; Pastan, I. Modulation of activity of the promoter of the human MDR1 gene by Ras and p53. Science 1992, 255, 459-462.

[81] Cadwell, C.; Zambetti, G.P. The effects of wild-type p53 tumor suppressor activity and mutant p53 gain-of-function on cell growth. Gene 2001, 277, 15-30.

[82] Deb, S.; Jackson, C.T.; Subler, M.L.; Martin, D.W. Modulation of cellular and viral promoters by mutant human p53 proteins found in tumor cells. J. Virol. 1992, 66, 6164-6170.

[83] Dittmer, D.; Pati, S.; Zambetti, G.; Chu, S.; Teresky, A.K.; Moore, M.; Finlay, C.; Levine, A.J. Gain of function mutations in p53. Nat. Genet. 1993, 4, 42-46. 